\title{
Digitalization of Education: Models and Methods
}

\author{
Vladimir V. Godin ${ }^{1 *}$, Anna E. Terekhova ${ }^{1}$ \\ ${ }^{1}$ State University of Management, 99 Ryazanskii prospect, Moscow, 109542, Russia
}

\begin{abstract}
The paper examines the possible effects of information and communication technologies (ICT) on educational institutions (four directions of impacts and four axes of measuring changespedagogy, technology, organization, and economics). The authors propose to use four classes of models to describe all forms of technology-based education and possible transformations of educational institutions under the influence of ICT to analyze the modern experience of digital transformation: a value chain model describing the primary and secondary activities of an educational institution; a diagram of added quality chains describing the sequence of actions carried out by an educational institution; a model of the routine loop of a teacher (employee) of an educational institution, describing his/her daily activities, taking into account the use of software products and computer and communication technology, displayed at the appropriate place in the value chain; the event chain of the process, detailing the description of the routine loops of teachers (employees) and trainees, describing the logic of their actions, incoming and outgoing information, information systems used, and all types of interactions in the educational process between a trainees and a teacher, a trainee and training material, and a trainee and his own himself. As a result, a tool has been created to describe and research all modern forms of technological education and their digital transformation.
\end{abstract}

Keywords: Digital transformation of education; Digital transformation of education process modeling; Technology-based education

\section{Introduction}

Education, as a branch of the economy and as a system and process of knowledge transfer, is subject to the same changes that are currently undergoing in all areas of human activity under the influence of information and communication technologies (ICT). First, education as an industry undergoes digitalization processes and becomes part of the digital economy. Second, the rapid development of ICT brings these technologies to the forefront as a tool for transforming the education process itself as a system of knowledge transfer. Third, due to its interdisciplinarity, ICTs serve as an object of study and change the content of educational programs for almost all profiles.

Possible directions of transformation of education under the influence of ICT are determined by four related areas within which it is possible to monitor changes in educational organizations (EOs): pedagogy, technology, management, and economics.

Within the framework of pedagogy, one can distinguish between traditional education, technology-based education, and hybrid models as models of convergence of traditional

*Corresponding author's email: godin@guu.ru, Tel.: +07 495-3778914, Fax.: +07 495-3778914 doi: 10.14716/ijtech.v12i7.5343 
education and technology-based education. The field of "technologies" describes the ICT used for the educational process. Changes in the organization are associated with the use of ICT for the management of educational institutions. The fourth area of change is the economic model of delivering or providing education. The changes in education in these four directions for different but interrelated dynamics that need to be studied.

It is possible to distinguish generations of technologies and link them with educational models as Taylor (2001) did: from printed materials and distance learning to electronic content and flexible learning models. It should be noted that the educational process can be divided into following phases: (1) development of educational content and its demonstration; (2) consolidation of educational material; (3) control of knowledge and activity; and (4) assessment. In this case, the technological strengthening of the educational process is mainly associated with the use of various software products for training at the appropriate phases of the educational process, for example, tutor programs and electronic textbooks, business games, semantic networks, glossaries, simulation and digital twins, subject-oriented systems, virtual and augmented reality, artificial intelligence, test programs, etc. (Gillpatrick, 2020; Newman, 2017).

Thus, the development of ICT has predetermined the evolution of forms and methods of technology-based education and the formation of a modern environment of an educational institution. The use of technology and automation play a significant role in increasing productivity in education and will continue to do so (Berawi, 2020). Specific types of such education can be described as a wide range of forms, for example, electronic self-education through video materials; training in social networks; training in virtual environments; distance learning; e-learning environments with a learning management system (LMS; e.g., Moodle, Sakai, Blackboard, WebCT, Canvas, etc.), and with a virtual educational environment (Schmidt and Tang, 2020).

A large number of studies have been devoted to the peculiarities of technology-based education. Their systematization was carried out on the basis of the Delphi expert evaluation method (Zawacki-Richter, 2009). In research scheme, there are three levels of classification of research names in the field of technology-based education. Research classes are defined at each such level:

1. Macro-systems and theories (access, equality, and ethics; globalization of education and cross-cultural aspects; educational systems and institutions; theories and models; and research methods and knowledge transfer).

2. Meso-management, organization, and technologies (management and organization; costs and benefits; educational technologies; innovations and changes; professional development and supervision; student -support services; and quality assurance).

3. Micro-teaching and learning (pedagogical design; interaction and communication in educational communities; and characteristics of trainees).

These three levels, with the corresponding classes of research directions, comprehensively describe and position all research and publications. There are reviews of research that match the specified levels and classes (Zawacki-Richter, 2009; ZawackiRichter and Naidu, 2016; Zawacki-Richter and Latchem, 2018; Fermín González, 2019; Yıldız et al., 2020; Bozkurt and Zawacki-Richter, 2021). These reviews highlight the concepts that repeat over time. These concepts include computer, students, ICT, schools, models or training, which combine various thematic areas and concepts, and individual and collective studies.

The modern idea of using ICT in education (in the industry, in the system, and in the process of knowledge transfer) is the example of digital transformation. First, the use of digital twins, virtual and augmented reality, human-machine interaction technologies etc. 
transforms the learning process itself. Second, the same technologies transform the functions and processes of an EO and therefore lead to the transformation of organization into a digital business company with continuous registration and identification of events, forecasting and decision-making based on event brokers, big data analytics, cloud computing, blockchains and smart contracts, artificial intelligence and machine learning, and other technologies. This work is focused mainly on the transformation of education itself as a system and the process of knowledge transfer.

The purpose of the work is to build models to describe the digital transformation of education and educational institutions. In the total volume of the global education market before the COVID-19 pandemic, the share of any form of technology-based education varied from 1 to $3 \%$. The forced transition to on-line education due to the pandemic has led to an expansion of the forms and the scope of technology-based education. Most likely, this will not lead to a long-term "technological revolution" (Altbach, Wit, 2020), but it may help strengthen the process of forming a small number of elite, offline educational institutions and a large number of mass online educational projects. In any case, considering the possibilities of digital transformation of education in the development strategies of educational institutions remains important and relevant. This relevance is explained by the fact that in modern conditions, the strategies of EOs are primarily determined by the capabilities of ITC used, but formulation of innovation strategy in education to increase productivity relies on both organizational and strategic innovations and innovations in information systems (Dachyar et al., 2015).

\section{Methods}

The process of education is considered as an object of the study, and its digitalization is considered as a subject.

The idea of a value chain (Porter, 1985) is suggested as a tool for studying the impact of ICT on educational institutions and the learning process as a kind of description of the integration of primary and secondary activities of an EO. Primary and secondary activities are the sequences of actions carried out by employees and teachers to achieve certain result (primary activity) and ensure this result (secondary activity).

The primary activity of an educational institution includes the following sequence of actions: marketing, advertising, recruitment, organization of training, methodological work, training, and work with graduates. Secondary activities of an educational institution are: procurement, maintenance of buildings and structures, creation and support of infrastructure, finance, HR management, and so on.

The description of the primary and secondary activities of an EO is possible not only through a value chain but also with the help of a value-added chain diagram (Scheer, 1998). In this case, two models of valued-added chains should be built-one for secondary activity and the other one for primary activity, which would reflect the same actions that were described in the value chain.

In practice, these representations are the models of the upper level. Top-level models can be detailed in-depth as required for the study. For example, training can be described as the following sequence of actions: content formation, demonstration of educational material, consolidation of educational material, and knowledge control. At some subsequent level of detail, "learning" will be described by the following sequence of actions: "interaction," "communication," "motivation," and so on. And, for example, the decomposition of the action "recruitment to an educational institution" will require, among other things, the use of "communication with applicants" and other clarifying actions.

Any actions described in the framework of top-level models relate to the functions, 
processes, or projects of an EO and are carried out by an individual employee (teacher) or a group of employees (teachers) - a personnel unit. The personnel unit's actions are repetitive and on a day-to-day basis. To perform these actions, the personnel unit is endowed with some procedures that describe the algorithm for performing the actioninformation and software (SW) products that support the logic of performing the action (procedure) and computing and communication resources, that is, hardware (HW) products. The personnel unit with the corresponding SW and HW forms a routine loop of the EO for the execution of the concrete action (Figure 1).

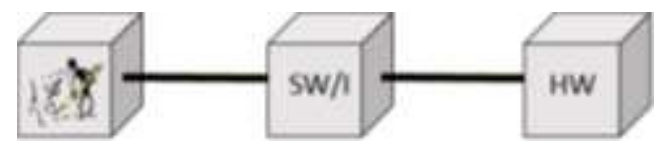

Figure 1 Routine loop of a personnel unit or trainee

The action quality can be influenced in three ways: (1) by increasing the degree of training of the personnel unit, (2) by improving SW, and (3) by performing a HW upgrade. A routine loop describes the ability of a personnel unit to perform an action using SW and HW. For trainees, it is also necessary to build routine loops within the "training" process. Such routine loops describe how (procedures) and with the help of which software and hardware the training is carried out. The procedures of trainees describe the observed types of interactions in the educational process: between trainees, between trainees and teacher, between trainees and learning material (Moore, 1997; Moore and Kearsley, 1996), and between trainees and their own selves (Lynch, 2002). Thus, a value chain with routine loops is the activity model of an EO (Figure 2).

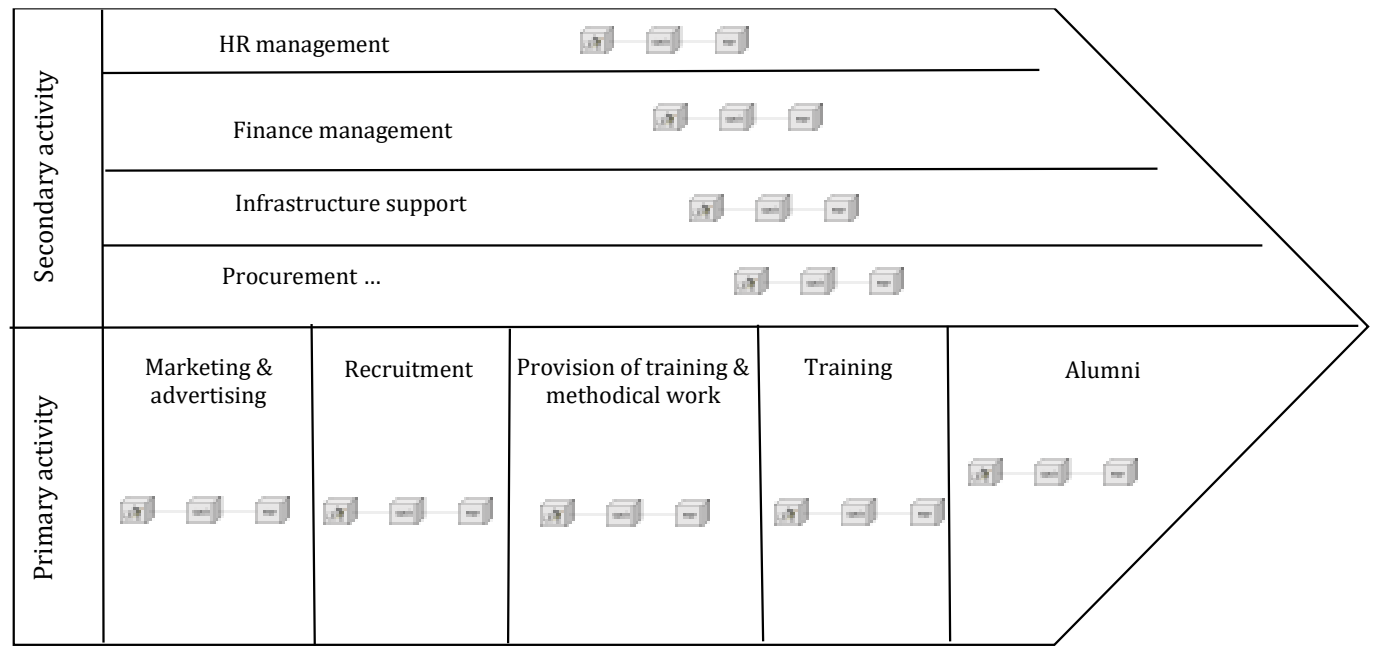

Figure 2 The value chain of an educational organization

The impact of ICT on education in the "pedagogy" part will be reflected in the sequence of actions in the primary activity and the nature of the details of the "training" action. The volume of investments in infrastructure is a consequence of the choice of an education model within a pedagogical dimension. This is described by routine loops of supporting activity. The organization and implementation of the educational process, and the activities of the educational institution itself, will be described by routine loops of all primary activities and part of secondary activities.

Further detailing of the EO activity model is associated with the representation of routine loops in the form of an event-extended event-driven process chain (Scheer, 1998). 
Process event chains are created for each action in the primary and secondary parts of the value chain. These models allow to algorithmize the description of routine loops of personnel units and trainees, describing the logic of their actions, incoming and outgoing information, information systems used, and all types of interactions in the educational process: between trainees, between trainees and the teacher, between the trainee and the training material, and between the trainee and his own self. An example of a value chain fragment for the "recruitment" process is shown in Figure 3.

The variability of eEPC models for the "training" action in the value chain is provided by the use of various ICTs to form routine loops of personnel units and trainees within this action.

As a result, different forms of value chains and different sequences of actions, set as routine loops of personnel units, allow to describe possible forms of technology-based education.

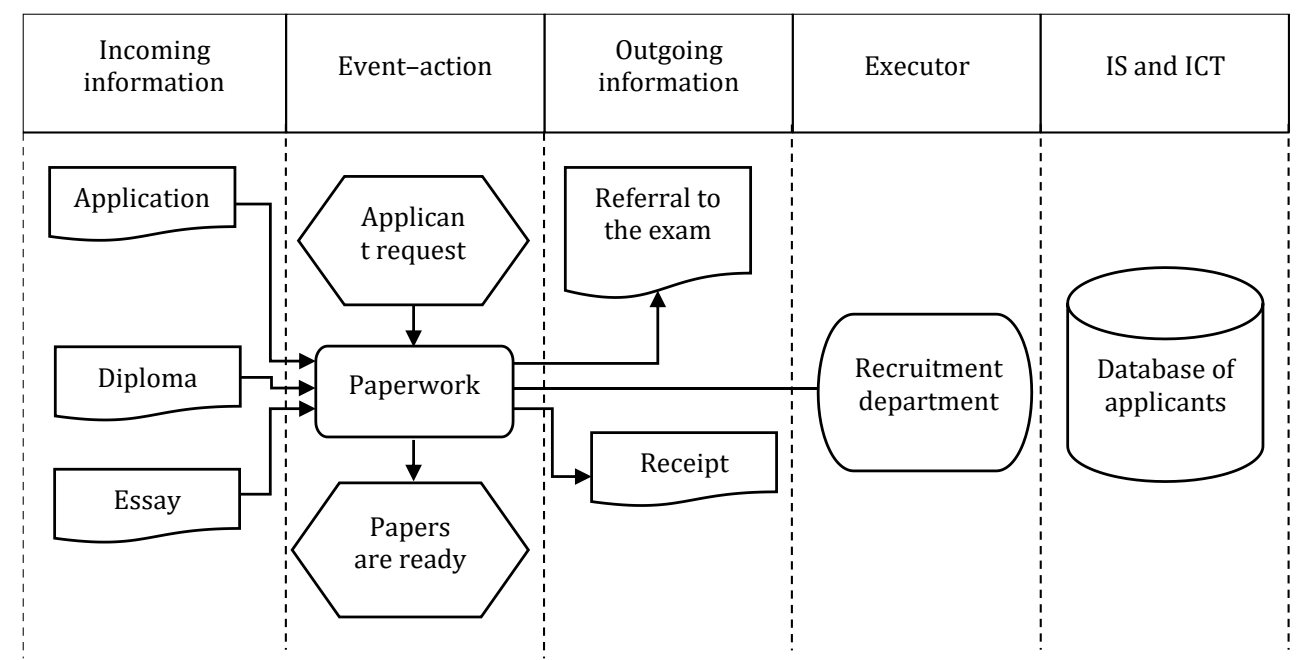

Figure 3 Example of a value chain fragment for the "recruitment" process

\section{Results and Discussion}

Thus, models proposed in the Section 2 allow ranking the extent of the use of ICT in an EO. In the case when changing the routine loops of personnel units and trainees under the influence of ICT does not affect their functionality and improves it according to certain parameters, we are talking about automation. The next stage in terms of the impact of ICT is informatization.

Informatization is a change in the strategy and business models (or their elements) under the influence of ICT. Informatization is based on automation. At this level of ICT impact, an information environment that provides new material for the work on content creation, training, knowledge verification, and qualification recognition is being created (see, e.g., Newman, 2017; Schmidt and Tang, 2020).

The latest at the moment stage of the ICT impact is digitalization. Digitalization includes the previous phases, automation, and informatization, and involves a fundamental change in the strategy and business model of an EO, as well as the learning process itself. The business model of an EO takes one of the forms of a digital company (e.g., a data-driven company), and the educational process involves the use of cyber-physical systems.

Digitalization involves development of digital education infrastructure (providing high-performance computing, big data, productive data storage systems, the Internet of Things, etc.), digital teaching materials, tools and services (intelligent learning systems and chatbots, artificial intelligence and machine learning systems, automated assessment, 
educational analytics, consulting systems, personal educational content, virtual reality technologies, digital twins, video games and simulators, blockchain technologies, etc.), and creation of new models for organizing educational work (changing access to information, network communities of trainees, mobile communication with the teacher, and individualization of educational work). A generalized description of the transformation of an EO under the influence of ICT is presented in Figure 4.

\begin{tabular}{|c|c|c|c|c|}
\hline \multicolumn{5}{|l|}{ Pedagogy } \\
\hline Forms of education & Traditional education & Hybrid forms of education & \multicolumn{2}{|c|}{ Technology-based education } \\
\hline $\begin{array}{l}\text { Observed types of } \\
\text { interactions in the } \\
\text { learning process }\end{array}$ & \multicolumn{4}{|c|}{$\begin{array}{l}\text { Between trainees, between trainees and teachers, between trainee and learning material, and between } \\
\text { trainee and his own self }\end{array}$} \\
\hline \multicolumn{5}{|l|}{ Technology } \\
\hline \multirow[t]{4}{*}{ Learning system } & \multicolumn{4}{|c|}{ Computer-based technologies, Web-based technologies, Stand-alone multimedia learning, et cetera. } \\
\hline & & \multicolumn{3}{|l|}{ Distance learning } \\
\hline & & & \multicolumn{2}{|l|}{ e-Learning } \\
\hline & & & & Smart Education \\
\hline \multirow[t]{3}{*}{ Extent of ICT use } & \multicolumn{4}{|l|}{ Automation } \\
\hline & & \multicolumn{3}{|l|}{ Informatization } \\
\hline & & & & Digitalization \\
\hline \multirow{2}{*}{$\begin{array}{l}\text { The object of } \\
\text { transformation }\end{array}$} & \multicolumn{4}{|c|}{ Routine loops of personnel units and trainees } \\
\hline & & \multicolumn{3}{|l|}{ Strategy and business model } \\
\hline \multicolumn{5}{|l|}{ Organization } \\
\hline ICT application & \multicolumn{4}{|c|}{ ICT for education organization management } \\
\hline Organizational forms & $\begin{array}{l}\text { Traditional educational } \\
\text { organization }\end{array}$ & $\begin{array}{l}\text { Advanced in terms of ICT } \\
\text { organization. Distance } \\
\text { learning organization }\end{array}$ & $\begin{array}{l}\text { On-line } \\
\text { educational } \\
\text { organization }\end{array}$ & $\begin{array}{l}\text { Digital business } \\
\text { organizations. Data- } \\
\text { driven company etc. }\end{array}$ \\
\hline \multicolumn{5}{|l|}{ Economy } \\
\hline & \multicolumn{4}{|c|}{$\begin{array}{l}\text { Economic models of education provision } \\
\text { Financial models of educational organizations }\end{array}$} \\
\hline
\end{tabular}

Figure 4 Transformation of an educational organization under the influence of ICT

Analysis of publications in the journals "International Review of Research in Open and Distance Learning," "Distance Education," "Computers \& Education," as well as some others allow us to trace the change in research directions in the field of application of ICT in education from "computer-based technologies" and "standalone multimedia learning" to "online learning in digital age." Modern research is largely devoted to issues related to open education and design, support, and quality assurance of online education with the introduction and use of educational technologies and digital tools. In general, research is distributed in the same areas of research at macro, meso, and micro levels that are described in section 1 .

At the macro level (systems and theories), research is dominated by general issues of open education (Bozkurt and Zawacki-Richter, 2021); pedagogical innovations and 
practices using technologies (Guàrdia et al., 2021); with the transformation of pedagogy (Tietjen and Asino, 2021). This can also include works on the "education for sustainable development," including issues of assessing the impact of the use of technology on campuses and the educational process (Suwartha and Berawi, 2019) and research on the impact of factors of digitalization of the regional economy on the competitiveness of local educational institutions and sustainable development (Koroleva and Kuratova, 2020).

At the meso level (management, organization, and technology), research focuses on the development, support, and quality assurance in online education (Bozkurt and ZawackiRichter, 2021). The details of the current state of research in the field of technology-based education are determined by 16 topics formed as a result of the analysis of 41925 peerreviewed publications (Gurcan et al., 2021). Among these topics, the leaders are the Massive Open Online Courser (MOOCs) "learning assessment", "e-learning systems", "learning algorithms", "learning factors" and "adaptive learning." As we can see, they relate to three interrelated areas of education transformation-pedagogy, technology, and organization. The largest increase in research is noted in the areas of "learning algorithms" and "learning factors." This indicates a movement towards personalized learning based on individualized and adaptive learning environments.

Micro-level research (teaching and learning) is mainly devoted to the implementation and use of educational technology, media, and digital tools. Thus, Cisel and Pontalier (2021) discuss modern educational platforms as knowledge markets, motivation, and strategies of teachers' behavior regarding such platforms. An indirect assessment of the implementation of the observed types of interactions noted by us in the educational process was carried out in the work of Martin et al. (2021). It analyzes the impact of synchronous and asynchronous online learning on learning outcomes. Preference is given to the synchronous learning. The study by Asvial et al. (2021) is devoted to the application of the theory of adoption and use of integrated technology. It considers students' perception of online learning technologies and evaluates the same. The studied students are classified according to age, gender, experience, and volunteerism. Four main factors of technology perception are studied: (1) expected productivity; (2) expected duration of effort; (3) social impact; and (4) facilitating conditions (confidence in infrastructure). As a result, the behavioral intention of the trainees to use or reject a particular technology is predicted.

The dynamics of changes in the dominant research topics on technology-based education is characterized by the following (Bozkurt, 2020): multimedia learning and educational design (1993-1999); convergence of educational technologies, distance education and online learning environments (1993-1999); changes in curricula under the influence of technology, educational technologies in higher and distance education, and research of educational technologies (2005-2009); online learning and higher education, integration of ICT and the full potential of educational technologies (2010-2014); intelligent educational technologies managed by data, big data, and learning analytics (2015-2019). The described dynamics of research changes reflects the processes of transformation of pedagogy, technology, organization, and economics in educational institutions and corresponds to the ideas of transformation shown in Figure 4. At the same time, existing publications on the digitalization of education are devoted to assessing its current state and trends in the online education market (see, e.g., Petrusevich, 2020).

In general, researches have not yet proposed a tool for modeling the transformation of education. Therefore, models proposed in this paper, which allow us to describe the transformation process and assess the impact of ICT on education, are original and valuable for practical use. It is proposed to use four classes of models to consider the potential of digital transformation of the EO, for example, to trace the role of ICT and related changes in 
the traditional EO and advancement in terms of ICT organization, online EO, digital business organizations. Also, the paper describes a fairly new model not widely used till now, the "routine loops," which describes the processes in an EO and all interactions within the educational process.

The areas of ICT impact-pedagogy, technology, organization, and economy have different potential and rates of change. Technologies (infrastructure, training tools, administrative tools, content creation tools, and corresponding systems and technologies for management) in an EO can be changed faster than any other else, however, it is slower and more difficult to build a pedagogical component-the concept of using training course and content management systems, virtual training enterprises, simulators and simulation models, synchronous and asynchronous communication systems, mass open online courses and corresponding platforms for these courses, and everything else for training purposes.

An essential component of the digitalization process is the economic model of education. Technology-based education seems to be cheaper for students than conventional education (Asvial et al., 2021) use the term "perceived cost"). And one of its social functions is to ensure the availability of education (providing logistics for foreign students and the possibility of virtual academic mobility). The advantages of such an education include the opportunity to use the best teaching experience at a low cost in a particular educational institution (MOOCs, joint content of university communities using the same course and content management systems (LMS $\backslash L C M S$ ), etc.). This is true for some forms of technology-based education, but in general, the costs of creating good content and infrastructure do not make this education cheaper than traditional education. However, the creation of educational content for new forms of technology-based education allows us to hope for leveling geographical boundaries and increasing the scale of appeal to students in global markets.

One of the significant results of changes under the influence of ICT in education is personalization of education and the management of students' experience, similar to the management of client experience. This means changes in pedagogy, technologies, and organization, leading to the concept of "smart education," within which it is possible to form and implement an individual educational trajectory.

The main participants in all changes under the influence of ICT in an EO are the teachers and the students. They must perceive innovations and have a certain level of digital literacy. One can observe quite a different perception of hybrid and online forms of education based on technologies by both of them (the teachers and the students). A number of studies (e.g., Dachyar et al., 2015) state the lack of adequate human resources in the implementation of technologies. In any form of education, the complexity of the teacher's work in the new conditions increases significantly. Teachers should prepare additional electronic content, record the result of trainings, and form and use procedures for obtaining and analyzing data on the educational process. There is an obvious increase in the information intensity and administrative burden for the teachers. In modern conditions, technology-based education takes the form of online education. In this case, the functions of external control on the part of the teacher are shifted toward the students themselves and are based on their motivation, which may not be stable. The teacher has additional emotional difficulties of conducting classes, hence the students' motivation decreases and new and additional distractions occur. In the absence of direct "live" communication, the culture and concepts of "university," "teacher," "scientific school," "leadership" are being destroyed. There is no unifying spatial physical place of learning that provides collaboration, and therefore, the possibility of forming socialization skills. In the case of online training, various personal interferences are possible for the students, splitting group work. Thus, technology-based 
educational models should be chosen based on specific users' needs and have specific content based on the correct methodology and approaches, interesting content, high level of motivation, a well-functioning software and technical base.

A significant problem of education digitalization is the applicability of forms of education based on technologies. Very often, these forms do not fully comply with the legislation and local acts of educational institutions. And for the real implementation of all these educational innovations, changes in academic planning, infrastructure, organization and organizational culture, teachers, students and employees, etc. are required.

\section{Conclusions}

ICT are an essential driver of the evolution of the modern education forms. Under their influence, the environment of functioning, EOs themselves, and the educational process are changing. The current phase of such an impact of ICT on the education sector is digitalization.

It is necessary to solve the problem of describing the impact of processes of manifestation of the ICT on education. Since modeling is a natural and often the only way to study the surrounding world, building models of such a manifestation seems to be a reasonable way of research. The proposed types of models allow to describe various forms of educational institutions that arise under the influence of ICT and the processes carried out in them, including the process of education with the observed types of interactions within the educational environment. Generalized organizational forms of educational institutions, depending on the nature of the use of ICT in them, are shown in Figure 4. Each of these forms will correspond to a specific value chain in terms of the routine loops used and the sequence of their use in the primary and secondary activities of an EO (mapping processes in the organization and the learning process).

Comparison between value chains with the respective value chains of competitors and the average industry value chain allows to assess the contribution of already used ICTs in EOs. It also allows to figure out in which part of the business processes and functions the EO lags behind or outstrips competitors or the average indicators for the industry. For example, in a generalized form, the value chain of a traditional educational institution is shown in Figure 2. A detailed "learning process" action is represented by a sequence of routine loops: development of educational materials, demonstration of educational content, consolidation of acquired knowledge, and knowledge control. Each of these routine loops can be transformed with the help of specialized ICTs. So, an EO that has implemented an LMS is changing all four routine loops within the learning process. And it will change the scale of the appeal to students, create technological barriers for other EOs to enter the same market, change the requirements for their own teachers and students, and much more. Further detailing of the description of the listed routine loops is carried out using eEPC models (as shown in Figure 3), which allows describing each routine loop in the following aspects: event-action (algorithm), input and output information for each action, personnel units or trainee for the execution of the action, and used ICT. Depending on the goals, the described models can be constructed, first, in the "modeling object" dimension: own EO, competitor organizations, description of a medium-sized conditional EO, and second, in the format "as is" or "to be."

The conducted research supports educational institutions in building a tool for deciding the required portfolio of ICT applications and realizing their digitalization program. Of course, when implementing this program, an educational institution should consider the applicability of the different forms of education based on technologies in personnel, technological, organizational, customer, and legal aspects. 


\section{References}

Altbach, P.G., Wit, H., 2020. Post Pandemic Outlook for HE is Bleakest for the Poorest. University Worldd News. The Global Window on Higher Education. Available Online at https://www.universityworldnews.com/post.php?story=20200402152914362, Accessed on December 21, 2021

Asvial, M., Mayangsari, J., Yudistriansyah, A., 2021. Behavioral Intention of E-Learning: A Case Study of Distance Learning at a Junior High School in Indonesia due to the Covid19 Pandemic. International Journal of Technology, Volume 12(1), pp. 54-64

Berawi, M.A., 2020. Empowering Healthcare, Economic, and Social Resilience during Global Pandemic Covid-19. International Journal of Technology, Volume 11(3), pp. 436-439

Bozkurt, A., 2020. Educational Technology Research Patterns in the Realm of The Digital Knowledge Age. Journal of Interactive Media in Education, 2020(1), pp. 1-17

Bozkurt, A., Zawacki-Richter, 0., 2021. Trends and Patterns in Distance Education (20142019): A Synthesis of Scholarly Publications and a Visualization of the Intellectual Landscape. The International Review of Research in Open and Distributed Learning, Volume 22(2), pp. 19-45

Cisel, M.T., Pontalier, D., 2021. Knowledge Marketplaces: An Analysis of the Influence of Business Models on Instructors' Motivations and Strategies. The International Review of Research in Open and Distributed Learning, Volume 22(3), pp. 142-158

Dachyar, M., Yadrifil, Pratama, N.R., 2015. Development of Strategy Model for Organizational. International Journal of Technology, Volume 6(2), pp. 284-290

Fermín González, M., 2019. Research on Virtual Education, Inclusion, and Diversity: A Systematic Review of Scientific Publications (2007-2017). The International Review of Research in Open and Distributed Learning, Volume 20(5), pp. 146-167

Gillpatrick, T., 2020. Innovation and the Digital Transformation of Education. The Journal of Limitless Education and Research, Volume 5(3), pp. 194-202

Guàrdia, L., Clougher, D., Anderson, T., Maina, M., 2021. IDEAS for Transforming Higher Education: An Overview of Ongoing Trends and Challenges. The International Review of Research in Open and Distributed Learning, Volume 22(2), pp. 166-184

Gurcan, F., Ozyurt, O., Cagitay, N.E., 2021. Investigation of Emerging Trends in the ELearning Field using Latent Dirichlet Allocation. The International Review of Research in Open and Distributed Learning, Volume 22(2), pp. 1-18

Koroleva, E., Kuratova, A., 2020. Higher Education and Digitalization of the Economy: The Case of Russian Regions. International Journal of Technology, Volume 11(6), pp. 11811190

Lynch, M.M., 2002. The Online Educator: A Guide to Creating the Virtual Classroom. New York: Routledge Falmer Studies in Distance Education

Martin, F., Sun, T., Turk, M., Ritzhaupt, A., 2021. A Meta-Analysis on the Effects of Synchronous Online Learning on Cognitive and Affective Educational Outcomes. The International Review of Research in Open and Distributed Learning, Volume 22(3), pp. 205-242

Moore, M.G., 1997. Theory of Transactional Distance. In D. Keegan, (ed.), Theoretical Principles of Distance Education. New York: Routledge, pp. 22-38

Moore, M.G., Kearsley, G., 1996. Distance Education: A Systems View. Belmont, CA: Wadsworth Pub. Co. Available Online at https://archive.org/details/distanceeducatio0000moor/page/n9/mode/2up, Accessed on December 21, 2021 
Newman, D., 2017. The Top Six Transformational Trends In Education, Forbes, (July). Available online at https://www.forbes.com/sites/danielnewman/2017/07/18/top6-digitaltransformation-trends-in-education/\#6912114e2a9a

Petrusevich D.A., 2020. Modern Trends in the Digitalization of Education. Journal of Physics: Conference Series, https://doi.org/10.1088/1742-6596/1691/1/012223, Accessed on

Porter, M.E., 1985. The Competitive Advantage: Creating and Sustaining Superior Performance. New York: Free Press

Reigeluth, C.M., Carr-Chellman, A.A., 2009. Instructional-design Theories and Models: Building a Common Knowledge Base, Volume 3, New York: Routledge

Scheer, A.W., 1998. Business Process Engineering Study Edition. Reference Models for Industrial Enterprises. Berlin, Heidelberg: Springer

Schmidt, J.T., Tang, M., 2020. Digitalization in Education: Challenges, Trends and Transformative Potential. In: Harwardt M., Niermann P.J., Schmutte A., Steuernagel A. Führen und Managen in der digitalen Transformation. Springer Gabler, Wiesbaden

Suwartha, N., Berawi, M.A., 2019. The Role of UI GreenMetric as a Global Sustainable Rankings for Higher Education Institutions. International Journal of Technology, Volume 10(5), pp. 862-865

Taylor, J., 2001. $5^{\text {th }}$ Generation Distance Education. Higher Education Series, Report No. 40, 2001, pp. 1-8. Available Online at http://www.c3l.unioldenburg.de/cde/media/readings/taylor01.pdf, Accessed on December 21, 2021

Tietjen, P., Asino, T.I., 2021. What Is Open Pedagogy? Identifying Commonalities. The International Review of Research in Open and Distributed Learning, Volume 22(2), pp. 185-204

Yıldız, G., Yıldırım, A., Akça, B.A., Kök, A., Özer, A., Karataş, S., 2020. Research Trends in Mobile Learning. The International Review of Research in Open and Distributed Learning, Volume 21(3), pp. 175-196

Zawacki-Richter O., Naidu S., 2016. Mapping research trends from 35 years of publications in Distance Education. Distance Education, Volume 37, pp. 245-269

Zawacki-Richter, O., 2009. Research Areas in Distance Education: A Delphi Study. International Review of Research in Open and Distance Learning, Volume 10(3), https://doi.org/10.19173/irrodl.v10i3.674

Zawacki-Richter, O., Bäcker, O., Vogt, S., 2009. Review of Distance Education Research (2000 to 2008): Analysis of Research Areas, Methods, and Authorship Patterns. International Review of Research in Open and Distributed Learning (IRRODL), Volume 10(6), pp. 2150

Zawacki-Richter, O., Latchem, C., 2018. Exploring Four Decades of Research in Computers \& Education. Computers \& Education, Volume 122, pp. 136-152 